\title{
Training effects on contrafreeloading in rats housed in operant chambers
}

\author{
ROBERT D. TARTE and CHARLES T. RASMUSSEN \\ University of Nevada, Las Vegas, Nevada 89154
}

\begin{abstract}
Four rats were trained to press a bar for food pellets and then were housed in operant chambers for 6 continuous days of choice-testing between obtaining pellets freely or by barpressing. There were two additional 3-day choice periods following more barpress training. It was found that (1) animals preferred to secure food by barpressing when initially placed in the choice situation and immediately following additional barpress training; (2) there was a subsequent decrease to very low levels of response-dependent food taken during choice testing; and (3) opening the chambers for daily maintenance during choice-testing caused a temporary increase in barpressing for food. Thus the previously reported stability of high rates of barpressing in the presence of free food is, at least in part, dependent upon short testing sessions.
\end{abstract}

Since Jensen's (1963) first study of the free vs. earned rewards, or contrafreeloading, phenomenon, there have been over $\mathbf{5 0}$ articles published concerning it [for a review, see Osborne (1977)]. A number of studies have demonstrated that animals will continue to respond operantly for food in the presence of identical free food and, in some cases, prefer earned over free food (e.g., Carder \& Berkowitz, 1970; Jensen, 1963; Neuringer, 1969; Singh, 1970; Tarte \& Snyder, 1972, 1973). The implications of these findings for learning and behavioral theories have been examined, and have called into question theoretical notions, such as those of Hull (1943), Logan (1960), and Tolman (1955), that an organism will prefer a less-effortful response when it has a more-effortful alternative response available which will secure an identical reward (Neuringer, 1969; Singh, 1970).

Many studies have employed training procedures in which animals received several free-food sessions and then a number of sessions of barpress training, prior to being placed in a choice situation in which they could obtain food pellets freely or by barpressing (Carder \& Berkowitz, 1970; Tarte \& Snyder, 1972, 1973), and they have generally found a great preference for obtaining food pellets via barpressing $(70 \%-90 \%)$.

A number of investigators have examined contrafreeloading in animals housed in operant chambers. Neuringer (1969) found that two experimentally naive pigeons learned to respond when housed in operant chambers for 20 days. Further, the birds

\footnotetext{
We wish to thank Charles Vernon for his help in conducting this research. Reprints may be requested from Robert D. Tarte, Department of Psychology, University of Nevada, Las Vegas, Nevada 89154.
}

attained relatively stable levels of responding within the first 3-4 days in the chambers. Subsequently, Kopp, Bourland, Tarte, and Vernon (1976) and McLaughlin, Kleinman, and Vaughn (1973) found the effect in naive rats, with no deprivation histories, which were housed in operant chambers, although in all cases the amounts of pellets obtained via barpressing were apparently low (10\% in the Kopp et al. study) in comparison to numbers of free food pellets consumed.

Maintenance of the contrafreeloading phenomenon has been examined in a few studies. Davidson (1971) found that rats maintained stable rates of responding over 87 daily choice sessions, and Tarte and Snyder (1973) found consistent barpressing levels over 10 daily choice sessions. When naive rats were housed in operant chambers, Kopp et al. (1976) found stable rates in two animals and an increase in barpressing after 30 and 48 days in the chambers in the other two. Coburn and Tarte (1976) found stable responding in eight rats over 25-30 continuous days of choice testing. However, Taylor (1972) found a decrease in barpressing over 15 daily 20 -min sessions following 1,000 continuously reinforced presses. This inconsistency may be due to procedural differences in that Taylor employed such short sessions and he interpolated a free-food session between barpress training and choice testing.

One variable that has been examined extensively in the earned vs. free rewards effect has been training level. The general finding has been that the more barpress training which rats receive prior to choice testing, with no intervening free-food experience, the more pellets will be obtained via the lever relative to free pellets during choice (e.g., Jensen, 1963; Mitchell \& White, 1977; Tarte \& Snyder, 1973).

In summary of the literature cited, (1) rats obtain 
$70 \%-90 \%$ of the pellets consumed during daily choice sessions by barpressing when they have received a number of successive daily sessions of training preceding the first choice session; (2) naive, nondeprived rats acquire the operant response and maintain a low percentage $(10 \%)$ of earned pellets when housed in operant chambers under choice conditions; (3) the level of contrafreeloading remains relatively stable whether there are daily choice sessions following training or choice is continuous over days with no training; and (4) prior training with either free or earned pellets increases the relative percentage of obtaining pellets via that mode during choice testing.

The study presented here was conducted in an attempt to reconcile disparate results reported above and to examine the contrafreeloading phenomenon in a new design. Animals were given the usual training in which they received three daily free-food training sessions followed by six daily barpress training sessions prior to being placed in operant chambers for 6 continuous days of choice testing. Then the animals were given a series of barpress training sessions and choice tests. We hypothesized that rats would barpress at a high level when initially placed in the choice situation due to extensive training, but that barpressing then would decrease to a lower stable level approximating that of naive animals housed in operant chambers $(10 \%)$. Of course, as they obtain less food via the bar, they should correspondingly obtain more freely. Further additional lever training should initially increase choice barpressing, followed by more rapid decreases to the established stable level.

\section{METHOD}

\section{Subjects}

The animals were four naive, male, albino rats of Wistar origin, weighing $225-275 \mathrm{~g}$ at the time of the experiment. The animals were housed singly in standard laboratory cages. When they were in their home cages, they had water available continuously and constant illumination.

\section{Apparatus}

Four BRS/LVE rat test cages, Model 143-20, served as operant chambers. The chambers were $30.14 \mathrm{~cm}$ wide, $24.8 \mathrm{~cm}$ long, and $26.9 \mathrm{~cm}$ high. A BRS/LVE retractable mouse lever, Model 123-05, was mounted on the back wall of each chamber. The $2.8-\mathrm{cm}$ wide, $1.0-\mathrm{cm}$-thick paddle projected through the right-hand side of the wall a distance of $2.2 \mathrm{~cm}$. The center of the bar was $4.2 \mathrm{~cm}$ from the right wall and $4.7 \mathrm{~cm}$ above the grid floor of the cage. The bar required a throw of $.16 \mathrm{~cm}$ with a minimum force of $0.20 \mathrm{~N}$.

BRS/LVE pellet feeders, Model 114-20 were mounted on each cage and deposited $45-\mathrm{mg}$ Noyes food pellets through a straight, open-ended metal tube mounted in the center of the rear wall. The end of the tube was $2.7 \mathrm{~cm}$ above the bottom of an $8.6-\mathrm{cm}$ diam, 1.5-cm-high metal food dish. The food dish was bolted to the floor grids. A free-food dish of the same dimensions was bolted to the floor grids in the left front corner of each cage. Water bottles were mounted on the outside left-rear walls of the chambers, with nondrip spouts protruding through the opening provided for a second bar. The spout extended $1.5 \mathrm{~cm}$ into the chamber and was $3.2 \mathrm{~cm}$ from the left wall and $4.7 \mathrm{~cm}$ above the grid floor.

Houselights in the chambers were on constantly. The chambers were housed in Coleman coolers, which served as sound-attenuating enclosures. The enclosures were ventilated by means of externally mounted fan. BRS/LVE electromechanical control and counting nodules were utilized in conjunction with cumulative recorders to operate the chambers and record responses.

\section{Procedure}

The four animals were handled and placed on 23-h food deprivation schedules for 1 week prior to the beginning of data collection. When the experiment began, the subjects received no food in their home cages, so that Noyes pellets were their only source of food. Other than when the animals were housed in the operant chambers, each daily experimental session lasted for $1 \mathrm{~h}$. The experiment consisted of three phases or series. In the first three daily sessions of Phase 1 , the free-food dishes were filled with $80045-\mathrm{mg}$ Noyes pellets. The bars were retracted during these sessions. On Day 4 , the rats were shaped to the bars. On Days 5 through 9, the animals barpressed for food pellets for $1 \mathrm{~h}$, that being their only source of food, providing a total of six sessions of barpress training. The free-food cups were present but empty during these six sessions. All barpressing during the experiment delivered pellets on CRF schedules. On the day following the last barpress-training session, the rats were placed in the chambers for 6 continuous days of choice-testing. During these 6 days that the animals were housed in the chambers, food pellets were continuously available via barpressing or from the free-food dish. After each 24-h period,the chambers were briefly opened to test the apparatus, empty and refill the free-food cups with 800 pellets, refill the water bottles, and clean the litter trays. The cumulative recorders were on continuously during choice testing. Spilled pellets found in the litter trays were subtracted from the appropriate free or earned totals; since the cups were located on opposite sides of the chamber, there was little difficulty in identifying the source of spilled pellets. Water was continuously available whenever the animals were in the operant chambers.

In Phase 2, following the 6 days of choice testing, the animals were returned to their home cages, and they received two daily $1-h$ sessions of barpress training in the operant chambers. Then they were returned to the operant chambers for 3 more continuous days of choice testing, identical to the original 6 choice days. In Phase 3 , the animals again were returned to their home cages and received two additional, daily $1-h$ barpress-training sessions in the operant chambers and 3 more continuous days of choice, after which the experiment was terminated.

It should be noted that barpressing was recorded continuously throughout choice testing, but that numbers of free-food pellets consumed were recorded only once every $24 \mathrm{~h}$. It would have been preferable to also record free-food consumption continuously, or at least hourly, but this was impossible due to equipment constraints and the probably disruptive effects of frequently opening the enclosures.

\section{RESULTS}

The four animals took from 451 to 696 pellets during the initial three daily sessions of free-food training, for a mean of 198 free pellets per rat per session. During the subsequent six barpress training sessions, the animals consumed from 1,306 to 1,560 pellets, for a mean of 235 earned pellets per animal per session, including the initial shaping session. In the two daily barpressing sessions following the 6 days of choice testing, the total number of pellets 


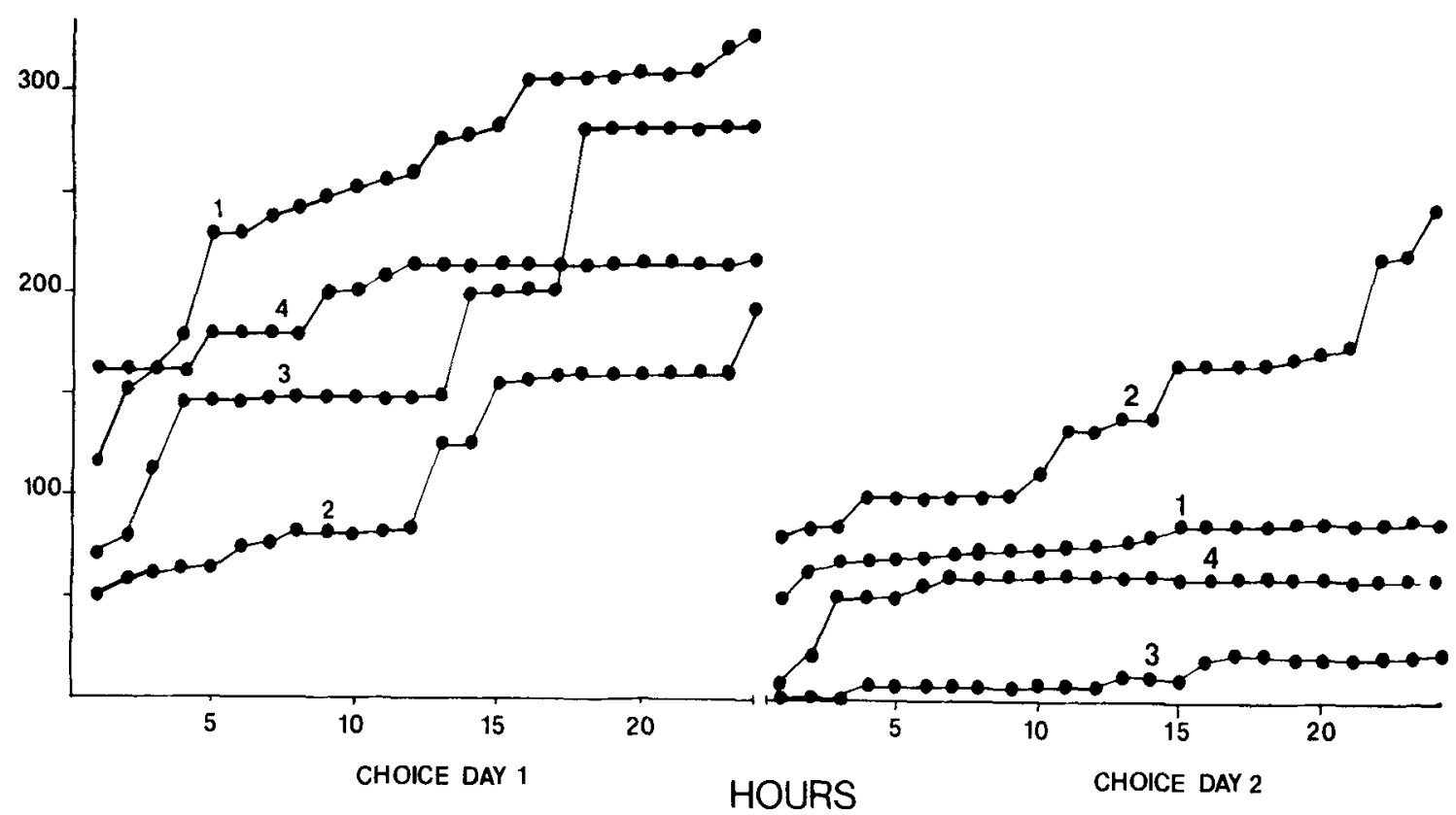

Figure 1. Cumulative numbers of barpresses per animal by hour for the first 2 choice days.

obtained ranged from 401 to 494 , for a mean of 220 per animal per session, and in the final two sessions of training following 3 additional choice testing days, the total range was from 451 to 528 , resulting in a mean of 243 pellets per rat per session.

In the first hour of the first choice-testing day, the four animals obtained $119,50,71$, and 162 pellets via barpressing. The four animals barpressed for $37 \%, 26 \%, 25 \%$, and $76 \%$ of their respective daily totals during the first hour of the first day. As can be seen from Figure 1, the rats generally decreased the number of pellets obtained by barpressing from the first hour of the first choice day over the remaining hours. In fact, there was only one instance of any animal taking more earned pellets in any $1-\mathrm{h}$ period than in the first hour (Rat 3, Hour 18). The cumulative curves represent only numbers of barpresses and not proportions of food obtained via barpressing.

The cumulative numbers of barpresses by animal by hour during the second choice day are also presented in Figure 1. Following opening of the chambers at the end of Day 1, two of the four rats made a number of barpresses during the first hour. Over the next four choice days, this pattern became more stable; all animals made a number of barpresses for food shortly after the chambers had been opened, and then made few during the remainder of each choice day.

Figure 2 presents the mean numbers of pellets consumed via the two modes during all choice days. During the initial 6 choice days, the animals gradually reduced the numbers of pellets obtained via barpressing and increased those taken freely. As has been mentioned, a large proportion of the barpressing pellets were obtained early in the choice days. The total number of pellets consumed remained fairly constant over the 6 days, although there was a slight successive decrease. The mean numbers per animal were $674,568,577,639,523$, and 575 for the 6 days, respectively. A two-factor, repeated-measures analysis of variance was applied to the data. The only statistically significant difference between choice days in total numbers of pellets consumed was between Days 1 and $5[F(5,15)=3.87, p<.05$, NewmanKeuls test]. The larger number of pellets consumed during the first choice day may reflect the fact that animals had previously been on 23-h deprivation schedules. The percentages of pellets obtained via barpressing were $38 \%, 18 \%, 20 \%, 27 \%, 9 \%$, and $8 \%$, respectively, for the initial 6 choice days. The animals consumed significantly more food obtained freely than via the bar, overall $[F(1,15)=450.29$, $\mathrm{p}<.001]$; the interaction between source of food and choice day was not significant $[F(5,15)=2.04]$.

Figure 2 also presents the overall results of the second and third series of 3 choice days, each following two barpress-training sessions. Two-factor, repeated-measures analyses of variance were applied to these data. In each of these choice series, the rats obtained signficantly more free than earned pellets overall [second series: $F(1,3)=107.9, p<.005$; third series: $F(1,3)=214.3, p<.001]$, and also showed significant decreases in total consumption, similar to the finding in the initial 6 choice-days. In the second series, rats consumed more pellets on Day 1 


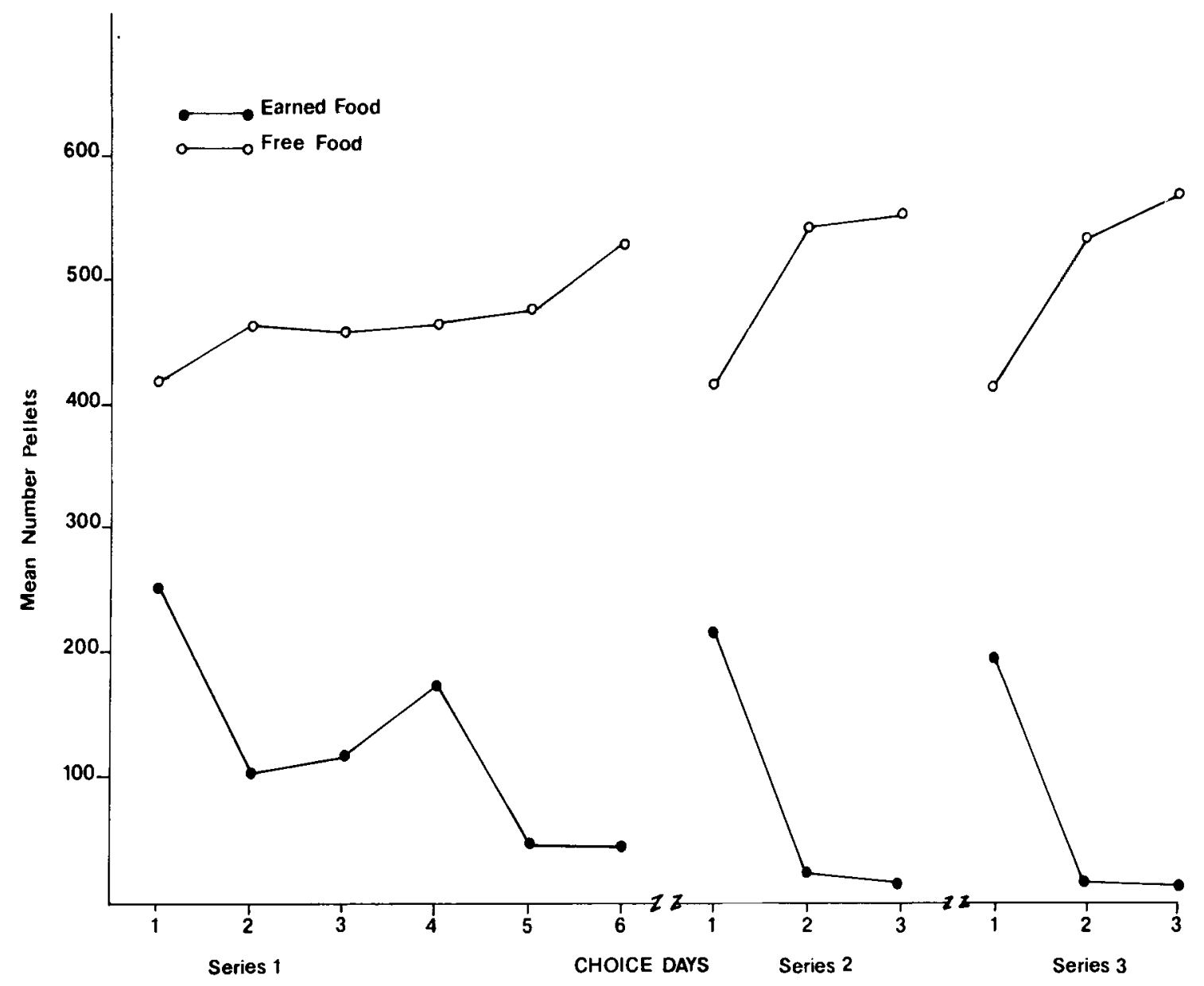

Figure 2. Mean numbers of pellets obtained by barpressing and freely by day for the three choice series.

than on Days 2 or $3[F(2,6)=7.69, p<.05$, and by Newman-Keuls test both $p<.05]$; in the third choice-series they also consumed more food on Day 1 than on Day 2 or Day 3, $[F(2,6)=6.69$, p $<$ .05 , and by Newman-Keuls test both $\mathrm{p}<.05$ ]. The interaction between food source and choice day was statistically significant only in the second choice series $[F(2,6)=8.16, p<.05]$. It was found that more pellets were obtained freely than via barpressing on each day and more earned pellets were consumed on the first choice day than earned pellets on the second or third choice days [Newman-Keuls, all $p<.05$ ].

As can be seen in Figure 2, the rats increased amount of free food and, correspondingly, decreased earned food over both choice series. The daily percentages of earned pellets for the second series were $34 \%, 4 \%$, and $3 \%$, and for the third series were $32 \%, 3 \%$, and $3 \%$, respectively. Furthermore, individual cumulative curves showed that in all of these choice days all animals obtained most of their earned food at the beginning of the day, following the chambers being opened, and usually during the first hour. It appears clear that barpress training increases the amount of barpressing initially during continuous choice testing, and that opening the chambers also increases immediate barpressing, a phenomenon possibly akin to "disinhibition."

\section{DISCUSSION}

It was hypothesized that following six daily sessions of barpress training, rats would initially obtain relatively large numbers of pellets by barpressing when placed in continuous choice testing. This hypothesis was supported. Animals made many barpresses for pellets during the first hour and then generally decreased responding throughout the first day. The same pattern was found at the beginning of the second and third choice sessions, following additional training. One explanation for these results might be that the previously conditioned approach responses to the free-food cup were extinguished during barpress training, when the cups were present but empty. Therefore, animals had to "rediscover" that the freefood cups were full and, thus, initially barpressed. This hypothesis does not seem tenable for two 
reasons. First, all animals exhibited exploratory behavior when first placed in the chambers and were observed to "discover" and eat free pellets before the chambers were closed; and second, the same pattern of responding occurred at the beginning of choice sessions in which subjects had not just previously experienced empty free-food dishes.

Of course, the subjects had been food deprived for $23 \mathrm{~h}$ prior to the beginning of each choice series; therefore the contrafreeloading rates observed during these initial periods may be partially confounded by deprivation levels. There was a slight weight loss in subjects during barpress training and during periods of 23-h food deprivation. However, there was no overall weight loss in the course of the 25 days in which Noyes pellets were the only source of food. The results appear to approximate those of Carder and Berkowitz (1970), Jensen (1963), and Tarte and Snyder $(1972,1973)$ and others, all of whom employed similar training procedures. It was impossible to calculate percentages of pellets secured via the bars continuously, because opening the chambers in order to record numbers of free pellets eaten would have disrupted the experiment. However, the numbers of barpresses during the first choice hour are similar to those which have been reported in the literature. In our laboratory, these numbers compare with levels previously obtained.

Our second hypothesis was that, following the initial high levels of obtaining pellets by barpressing, the animals would decrease barpressing and correspondingly increase free-food consumption. This hypothesis was also supported by the data. The subjects decreased barpressing over the first 6 choice days to very low levels. By Day 5, the animais were obtaining approximately the same proportion of pellets via the lever as reported by Kopp et al. (1976) in a study in which naive, nondeprived rats were given 100 days of continuous choice testing.

The third hypothesis was that additional barpress training would result in increased barpressing in choice testing immediately following the additional training. This hypothesis was clearly supported. As can be seen in Figure 2, many barpresses were made on Day 1 of the second and third choice series. In this case, the animals received two additional sessions of training prior to each choice series. Increased habit strength for the lever resulted in increased barpressing. This finding is in accord with other studies showing the effects of training on contrafreeloading (e.g., Jensen, 1963; Mitchell \& White; 1977; Tarte \& Snyder, 1973).

We found that animals obtained progressively fewer pellets and a lower proportion of pellets via barpressing as time in the choice situation continued, in the original 6-day period and in the two subsequent choice periods. The initial preference for response-contingent food, then was not maintained. Previous studies which have reported stable maintenance have either employed short, daily sessions of training and testing or long-term continuous lesting wiih no previous training. Following daily training sessions, we found high levels of barpressing and then a decrease to the level reported in studies in which the animals were housed in operant chambers with no previous training. It appears that rats only maintain high levels of responding following intensive training and when they are tested for only short daily periods. Further, with additional lever training, high levels of barpressing are again attained in choice testing, but the subsequent decrease to prevailing lower levels occurs more quickly.

Whenever the chambers were opened during choice testing (every $24 \mathrm{~h}$ ), there was an immediate increase in barpressing for pellets following closing of the chambers. Then animals tended to decrease number of responses throughout the 24 -h period until the chambers were opened again. This phenomenon appears to be similar to that classically termed as disinhibition, except that no experimental extinction has occurred. In this case, there is a diminution of responding while animals secure food from an alternative source, and then a temporary increase in barpressing following the introduction of novel, extraneous stimulation. It would be interesting to test whether the presentation of a discrete, novel stimulus increases contrafreeloading following similar training procedures.

The animals were quite consistent in responding, and progressively became more consistent as the experiment continued, both within and between subjects. There was no instance of overlap between sources of food for any rat on any choice day. That is, every animal on every choice day obtained more free than earned pellets.

The most prominent aspect of the present study is that the relatively high, stable levels of barpressing in the choice situation following barpress training (in the design of Carder \& Berkowitz, 1970) appear to be dependent, at least in part, on short (1-h) daily testing sessions. Furthermore, even this shortsession response pattern may be a stimulus-related phenomenon akin to "disinhibition"; our data indicate that nondeprived subjects in a choice situation whose barpressing has declined to very low levels will show a distinct burst of responding following opening of the operant chambers.

It appears that contrafreeloading in rats, at least preferences for response-dependent food, is a function of training, rearing conditions, and, now, testing animals for short periods. When rats are housed in operant chambers for extended periods of time, they ultimately prefer response-independent food, making what might be considered the less-effortful response, 
unless they have been reared in an impoverished environment (see Coburn \& Tarte, 1976). However, animals will continue to secure some food via the response-dependent source, albeit a small proportion of the food consumed.

\section{REFERENCES}

CARDER, B., \& Berkowitz, K. Rats' preference for earned in comparison with free food. Science, 1970, 167, 1273-1274.

Coburn, J. F., \& TARTE, R. D. The effect of rearing environments on the contrafreeloading phenomenon in rats. Journal of the Experimental Analysis of Behavior, 1976, 26, 289-294.

DAvidson, A. B. Factors affecting keypress responding by rats in the presence of free food. Psychonomic Science, 1971, 24, 135-137.

Hull, C. L. Principles of behavior. New York: AppletonCentury-Crofts, 1943.

Jensen, G. D. Preference for bar pressing over "freeloading" as a function of number of rewarded presses. Journal of Experimental Psychology, 1963, 65, 451-454.

Kopp, J., Bourland, G., Tarte, R. D., \& Vernon, C. R. Acquisition of barpressing in nondeprived rats. Psychological Record, 1976, 26, 49-54.

LogaN, F. A. Incentive. New Haven: Yale University Press, 1960.

Mclaughlin, R. J., Kleinman, K. M., \& Vaughn, L. G. Effects of prior training at lever pressing on rats' subsequent responding for food or water in the presence of free rewards.
Proceedings of the 81st Annual Convention of the American Psychological Association, 1973, 8, 845-846.

Mitchell, P., \& White, K. G. Responding in the presence of free food: Differential exposure to the reinforcement source. Bulletin of the Psychonomic Society, 1977, 10, 121-124.

Neuringer, A. J. Animals respond for food in the presence of free food. Science, 1969, 166, 399-401.

OSBORNE, S. R. The free food (contrafreeloading) phenomenon: A review and analysis. Animal Learning \& Behavior, 1977, 5, 221-235.

Singh, D. Preference for barpressing to obtain reward over freeloading in rats and children. Journal of Comparative and Physiological Psychology, 1970, 73, 320-327.

TARTE, R. D., \& SNYDER, R. L. Barpressing in the presence of free food as a function of food deprivation. Psychonomic Science, 1972, 26, 169-170.

TARTE, R. D., \& SNYDER, R. L. Some sources of variation in the bar-pressing versus freeloading phenomenon in rats. Journal of Comparative and Physiological Psychology, 1973. 84, 128-133.

TAYLOR, G. T. A limitation of the contrafreeloading phenomenon. Psychonomic Science, 1972, 29, 173-174.

Tolman, E. C. Principles of performance. Psychological Review, $1955,62.315-326$.

(Received for publication April 19, 1978; revision accepted July 13,1978 .) 